\title{
Formulation, Optimization and Evaluation of Multiple Emulsion of Atorvastatin
}

\author{
Sivapriya.S*, Daisy P.A, Praveen Raj R, Betty Carla \\ Department of Pharmaceutics, St. Joseph'S College of Pharmacy, Cherthala, India. \\ *Corresponding author's E-mail: sivapriyasujith92@gmail.com
}

Received: 18-07-2020; Revised: 22-09-2020; Accepted: 04-10-2020; Published on: 20-10-2020.

\begin{abstract}
Multiple emulsions are often stabilized using a combination of hydrophilic and hydrophobic surfactants. The ratio of these surfactants is important in achieving stable multiple emulsions. Atorvastatin was selected as a model drug to study the potential of multiple emulsions to improve bioavailability with the hypothesis that improvement of drug release profile will reflect the enhancement of bioavailability of the drug. The objective of this study was to prepare multiple emulsion of Atorvastatin by two step emulsification using non-ionic surfactants, and evaluate for stability, percentage drug entrapment, In-Vitro \& Ex-Vivo drug release. The different variables like, rpm, concentration of surfactants and ratio of aqueous and oil phase were optimized to get the stable emulsion with high drug release and less particle size. The study concluded that stable multiple emulsion with high drug release can be prepared by two step emulsification method using Span80 as primary emulsifier at 30:70 phase volume ratio of internal phase: external phase with optimized speed of stirring at $3000 \mathrm{r} / \mathrm{min}$ for $15 \mathrm{mins}$ for primary emulsification. The optimized formula were used for the preparation of multiple emulsion with the optimum drug release characteristics.
\end{abstract}

Keywords: Multiple Emulsion; Non-ionic Surfactant; Atorvastatin, Optimization.

QUICK RESPONSE CODE $\rightarrow$

DOI:

10.47583/ijpsrr.2020.v64i02.003

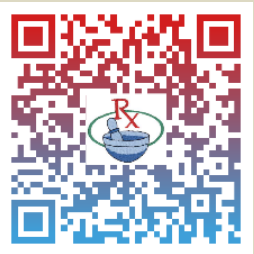

DOI link: http://dx.doi.org/10.47583/ijpsrr.2020.v64i02.003

\section{INTRODUCTION}

$\mathrm{n}$ ideal dosage regimen in the drug therapy of any disease is the one which immediately attains the desired therapeutic concentration of drug in plasma (or in the site of action) and maintains it constant for the entire duration of treatment. For many decades, treatment of an acute disease or a chronic illness has been mostly accomplished by delivery of drugs to patients using various pharmaceutical dosages forms, including tablets, capsules, pills, suppositories, creams, ointment ,liquids, aerosols, and injectable, as drug carriers. Even today these conventional drug delivery systems are the pharmaceutical products commonly seen in the prescription and over-the-counter drug market place. This type of drug delivery system is known to provide a prompt release of drug. Therefore, to achieve as well as to maintain the drug concentration within the therapeutically effective range needed for treatment. When administered into the body, this gives high therapeutic efficacy with minimal toxicity. It gives better selectivity of pharmacological activity, and improves patient compliance by reducing the dosing intervals.

Multiple emulsions are defined as emulsions in which both types of emulsions, i.e. water-in oil (w/o) and oil-inwater $(\mathrm{o} / \mathrm{w})$ exist simultaneously. They combine the properties of both w/o and o/w emulsions. These have been described as heterogeneous systems of one immiscible liquid dispersed in another in the form of droplets, which usually have diameters greater than 1 $\mu \mathrm{m}$.

Multiple emulsions were determined to be promising in many fields, particularly in pharmaceutics and in separation science. Their potential biopharmaceutical applications include their use as adjuvant vaccines, as prolonged drug delivery systems, as sorbent reservoirs in drug overdose treatments and in mobilization of enzymes. Multiple emulsions were also investigated for cosmetics for their potential advantages of prolonged release of active agent, incorporation of incompatible materials and protection of active ingredients by dispersion in internal phase. ${ }^{1}$

Atorvastatin, a synthetic HMG Co-A Reductase inhibitor, is widely used in treatment of primary hypercholestremia and Dyslipidaemia. Atorvastatin is indicated as adjunctive therapy to diet for the treatment of patients with elevated serum triglyceride levels (Fredrickson Type IV). Oral bioavailability of Atorvastatin is very low (Only 14\%) due to its presystemic clearance in gastrointestinal mucosa and first pass hepatic metabolism. However, very few studies have been reported for enhancement of bioavailability of poorly water soluble drugs by formulating as multiple emulsions.

The present study is based on the hypothesis that improvement of in vitro as well as ex vivo (using rat intestines) dissolution profile of AT and it will reflect the enhancement of bioavailability of the drug.

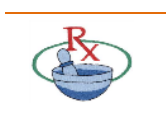




\section{MATERIALS AND METHODS}

\section{Materials}

Atorvastatin calcium was obtained as the gift sample from Sance laboratories pvt. limited, Kerala, Tween 80 from Merklimite, Mumbai, Span 80 from Chemdyes Corporation and light liquid paraffin from Spectrum reagents chemicals. All the reagents and chemicals were of analytical grade.

\section{Methods}

\section{Preparation of Multiple Emulsions}

Multiple emulsions were prepared by two step emulsification process. First primary emulsion is formulated in a high stirring speed. Then the so formed primary emulsion is again emulsified to get multiple emulsions. $^{3}$

\section{Step 1 (Preparation of Primary Emulsion)}

- $45 \mathrm{ml}$ of distilled water containing $50 \mathrm{mg}$ of drug was gradually added to $55 \mathrm{ml}$ of oil phase containing primary emulsifier span $80(4 \mathrm{ml})$ and $25 \mathrm{mg}$ of drug with continuous stirring at 5000rpm for $5 \mathrm{~min}$.

- Primary emulsion(w/o) was formulated.

\section{STEP 2 (Secondary Emulsification)}

- $20 \mathrm{ml}$ viscous primary emulsion was emulsified further with an external aqueous phase containing secondary emulsifier (Tween 80 ) and $25 \mathrm{mg}$ drug with continous stirring at $1000 \mathrm{rpm}$ for 10 minutes.

- Water / oil/ water (w/o/w) multiple emulsion was formed.

Formulation of multiple emulsions with optimized primary emulsion

Eight batches (F1-F8) of primary emulsions was prepared by placing the drug concentration as constant $(100 \mathrm{mg})$ whereas, the rpm, concentration of surfactant $\&$ ratio of aqueous and oil phase had taken as variables. The particle size \& drug release from the emulsion was kept as the response factors. By using the design expert (stat ease) software, the optimization profiles were obtained. The optimized formula had used for the preparation of multiple emulsion of Atorvastatin with good particle size $\&$ drug release profile. Suitable flavouring agents were added to obtain palatability to multiple emulsion. Variables for optimization are given in table 1 and formula for optimum batch of primary emulsion is given in table 2.

Table 1: Variables for optimization

\begin{tabular}{|l|c|c|c|}
\hline & Variables & $\mathbf{+ 1}$ & $\mathbf{- 1}$ \\
\hline X1 & RPM & 5000 & 3000 \\
\hline X2 & Surfactant concentration & $4 \mathrm{ml}$ & $12 \mathrm{ml}$ \\
\hline X3 & Ratio of aqueous \& oil phase & $30: 70$ & $45: 55$ \\
\hline
\end{tabular}

\section{Preparation of calibration curve}

$10 \mathrm{mg}$ of AT dissolved in sufficient quantity of methanol and volume was made up to $100 \mathrm{ml}$ with methanol. From the stock solution, different dilutions from $2-20 \mu \mathrm{g} / \mathrm{ml}$ was prepared with the same diluting medium to obtain a calibration curve. Absorbances of solution were spectrophotometrically determined at $247.5 \mathrm{~nm}$.

\section{Microscopic Analysis}

Microscopic analysis was carried out using an research microscope (labomed LX 300) combined with a computer imaging system, and observations were made at $40 \mathrm{X}$ magnification after diluting in the appropriate amount of external phase of the emulsion. The shape and homogeneity of the multiple droplets is followed immediately after the preparation of the multiple emulsion formulations. A picture of the multiple emulsion formulation was taken.

\section{Droplet Size Analysis}

The mean droplet size of the multiple emulsion formulations was determined using particle size analyzer (Malvern Mastersizer) for the freshly prepared formulation.

\section{pH}

$\mathrm{pH}$ of the freshly formulated emulsion was done using digital $\mathrm{pH}$ meter. Here the digital $\mathrm{pH}$ meter is calibrated to neutral $\mathrm{pH}$ by dipping the glass electrode end in freshly prepared distilled water for several minutes. Then the glass electrode is dipped in the emulsion and $\mathrm{pH}$ reading was noted.

\section{Entrapment efficiency}

Entrapment efficiency was determined by taking freshly prepared W/O/W multiple emulsions and immediately centrifuged at $4000 \mathrm{r} / \mathrm{min}$ for $10 \mathrm{~min}$. Then $1 \mathrm{ml}$ of the aqueous phase (the lower layer) was precisely withdrawn through $2 \mathrm{ml}$ hypodermic syringe and diluted properly with $0.1 \mathrm{~N} \mathrm{HCl}$. The solution was filtered with a whatman filter paper and drug content was analyzed on UV spectrophotometer at $240 \mathrm{~nm}$. The Encapsulation Efficiency was determined by following equation:

$\% \mathrm{EE}=[($ Total drug incorporated -Free Drug)/ Total drug $]$ $X 100$

\section{Invitro drug release study}

The in vitro drug release study was carried out on a simple dissolution cell using cellophane membrane. Prior to release studies, the cellophane membrane was soaked in distilled water for 6 hours, washed frequently 4 times by changing distilled water, then immersed in $5 \% \mathrm{v} / \mathrm{v}$ glycerol solution for at least $60 \mathrm{~min}$ and washed finally with 5 portions of distilled water. Freshly prepared multiple emulsion $(15 \mathrm{ml})$ was added to donor chamber, made up of a hollow glass tube $(2.5 \mathrm{~cm}$ in diameter and $10 \mathrm{~cm}$ in length) and membrane was tied on bottom end of the tube with a nylon string. This tube was dipped into 
$1000 \mathrm{ml}$ vessel containing $900 \mathrm{ml}$ of PBS pH 6.8 and was stirred at $75 \mathrm{rpm}$ on a magnetic stirrer and maintained at $37{ }^{\circ} \mathrm{C}$ which acted as receiving chamber. Aliquots of $1 \mathrm{ml}$ were collected from receiving chamber at predetermined time intervals and the drug contents determined on UV spectrophotometer at $240 \mathrm{~nm}$ after suitable dilution. ${ }^{5}$

\section{Determination of Drug Release Mechanism ${ }^{6,7}$}

In order to understand the mechanism of drug release, Invitro drug release data were treated to kinetic models such as zero order, first order and Higuchi model and korsmeyerpeppa"s model.

\section{Ex Vivo Release study}

Drug release study was performed on the rat ileum by following perfusion method. The special apparatus consist of $U$ shaped glass tube having $1 \mathrm{~cm}$ inner diameter with cannulated cut on the upper half arm of the $U$ tube. ${ }^{8}$

\section{Viscosity study}

Viscosity is a principal parameter when any flow measurements of fluids, such as liquids, semisolids. Gases and even solids are made. Brookfield deals with the liquids and semisolids. Brookfield viscosity usually refers to a viscosity measurement performed with a Brookfield Viscometer, sometimes referred to as a Brookfield viscosimeter. There are several models of viscometer available from Brookfield but the majority operates in the same manner: the viscometer motor rotates the spindle at a defined speed (measured in rpm) or shear rate and the viscometer measures the resistance to rotation and reports a viscosity value. ${ }^{9}$

\section{Stability study of optimized formulation}

Formulations were subjected to stability studies for a period of 30 days. The samples were withdrawn after 30 days and were evaluated $\mathrm{pH}$, entrapment efficiency and release profile.

\section{RESULTS AND DISCUSSION}

The Drug (Atorvastatin) powder was examined for its organoleptic properties like colour, and odour and it is observed that the Atorvastatin was white amorphous powder. The sample was quantitatively tested for its solubility in various solvents. Solubility study in different solvents revealed that it is freely soluble in methanol, slightly soluble in alcohol and insoluble in distilled water. The melting point of Atorvastatin Calcium was found to be 159.2-160.7.

\section{Preparation of calibration curve}

Absorbances of solution were spectrophotometrically determined at $247.5 \mathrm{~nm}$. A standard calibration curve for the drug was obtained by measuring absorbance at $247.5 \mathrm{~nm}$ and by plotting the graph of absorbance Vs concentration.

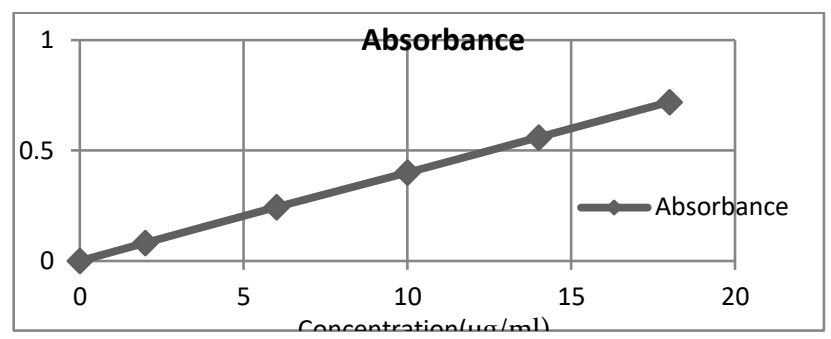

Figure 1: Calibration curve of Atorvastatin

\section{Evaluation of Multiple Emulsions}

\section{Microscopic Analysis}

Microscopic analysis was carried out using an research microscope (labomed LX 300), and observations were made at $40 \times$ magnification after diluting in the appropriate amount of external phase of the emulsion the image taken via microscope.

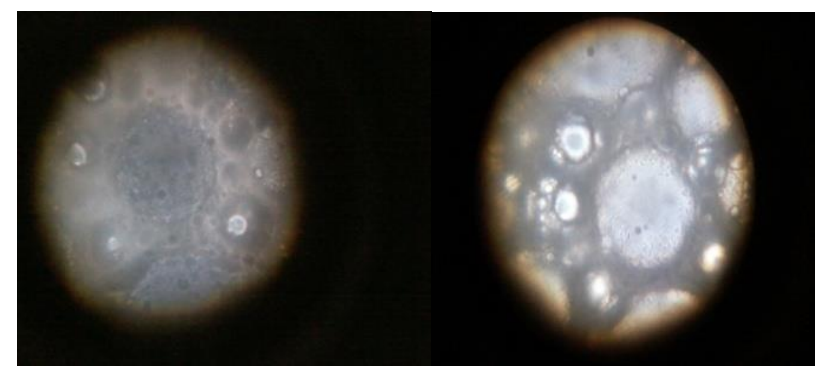

Figure 2: Microscopic images of multiple emulsions

Table 2: Formula for optimum batch of primary emulsion

\begin{tabular}{|c|c|c|c|c|c|}
\hline Number & Rpm & $\begin{array}{c}\text { Conc. of } \\
\text { surfactants }(\mathbf{m l})\end{array}$ & $\begin{array}{c}\text { Ratio of aqueous } \begin{array}{c}\text { Particle size } \\
\text { oil phase(ml) }\end{array} \\
(\boldsymbol{\mu m})\end{array}$ & $\begin{array}{c}\text { Drug release } \\
(\%)\end{array}$ \\
\hline 1 & 3000 & 4 & $30: 70$ & 5.26 & 84.13 \\
\hline
\end{tabular}

Table 3: Mean droplet size of emulsion

\begin{tabular}{|c|c|c|c|c|c|c|c|c|c|c|}
\hline SI. No & 1 & 2 & 3 & 4 & 5 & 6 & 7 & 8 & 9 & 10 \\
\hline Size $(\boldsymbol{\mu m})$ & 12.7 & 14.7 & 16.4 & 11.2 & 10.3 & 11.3 & 5.5 & 5.4 & 6.4 & 7.5 \\
\hline
\end{tabular}

Table 4: Cumulative Drug Release of Atorvastatin Multiple emulsion (Exvivo)

\begin{tabular}{|c|c|c|c|c|c|c|c|c|c|}
\hline Time & 0 & 15 & 30 & 45 & 60 & 120 & 180 & 240 & 300 \\
\hline \%CDR & 0 & 5.3 & 10.0 & 15.5 & 29.1 & 38.5 & 50.6 & 76.5 & 88.9 \\
\hline
\end{tabular}




\section{Droplet Size Analysis}

The mean droplet size of the multiple emulsion formulation was determined using stage micrometer and eyepiece micrometer for the freshly prepared formulation. The mean droplet size of multiple emulsions was $7.8 \mu \mathrm{m}$. The obtained droplet sizes are given in table3.

\section{pH}

$\mathrm{pH}$ of the freshly formulated emulsion was done using $\mathrm{pH}$ paper and it was found to be 8 .

\section{Entrapment efficiency}

After formulating Atorvastatin multiple emulsions, the drug content was estimated by UV spectrophotometer at $\lambda$ $\max 247.5 \mathrm{~nm}$. The Entrapment efficiency of multiple emulsions was $88.5 \%$.

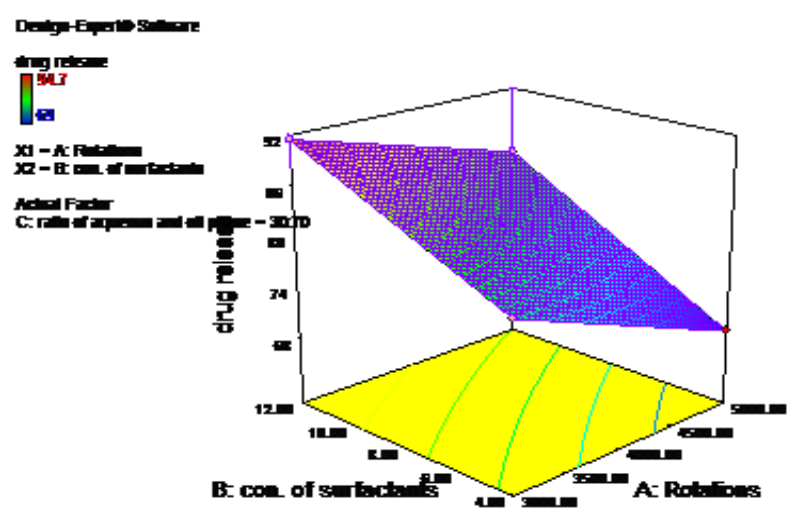

Figure 3: 3D plot of drug release

\section{In-vitro drug release studies}

In- vitro drug release studies were carried out in PBS of $\mathrm{pH}$ 7.4 as the dissolution medium. Studies were performed as per the procedure described in methodology.

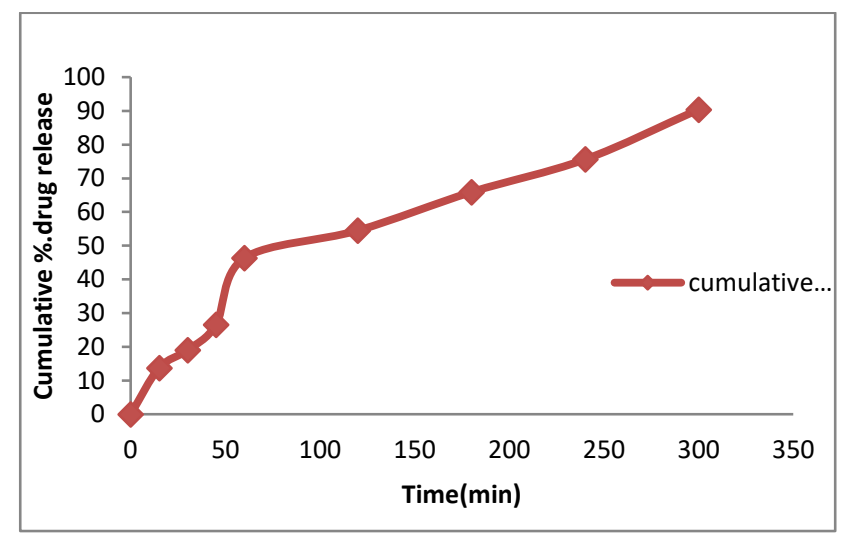

Figure 4: Invitro Cumulative drug release.

\section{Ex vivo drug release study}

Exvivo release studies were carried out by using the $U$ shaped apparatus. The rat ileum was tied in this apparatus and multiple emulsion was filled in it. The Multiple emulsions was filled in the ileum and placed inside the dissolution vessel with $\mathrm{pH}$ 7.4phosphate buffer. The drug released in the media was measured. The cumulative drug release at various time intervals are mentioned in table4.

\section{Viscosity}

Viscosity of ME was determined by using the Brookfield viscometer by selecting the spindle number and rpm. The viscosity of the formulation at different $\mathrm{rpm}$ has performed and is given in table 5 .

Table 5: Viscosity of the formulation

\begin{tabular}{|c|c|c|c|}
\hline rpm & Spindle Number & Viscosity(Cp) & Torque\% \\
\hline 100 & 18 & 16 & 53.5 \\
\hline 50 & 18 & 22 & 36.6 \\
\hline 60 & 18 & 7 & 14 \\
\hline
\end{tabular}

\section{Kinetic Modeling}

The results obtained of in vitro release studies were attempted to fit into various mathematical models. From the results given in table 6 , it is clear that the drug release shows first order kinetics for the formulation.

Table 6: Model fitting for the release profile of Atorvastatin Multiple Emulsion

\begin{tabular}{|c|c|c|c|c|}
\hline \multirow{2}{*}{ Formulation } & \multicolumn{4}{|c}{ Correlation coefficient(r)value } \\
\cline { 2 - 5 } & $\begin{array}{c}\text { Zero } \\
\text { order }\end{array}$ & $\begin{array}{c}\text { First } \\
\text { order }\end{array}$ & Higuchi & $\begin{array}{c}\text { Korsmeyer } \\
\text { Peppas }\end{array}$ \\
\hline ME & 0.823 & 0.967 & 0.957 & 0.952 \\
\hline
\end{tabular}

\section{Stability study}

Prepared formulation was subjected to stability study for 30days. Sample was withdrawn after 30 days and was evaluated for parameters like particle size, $\mathrm{pH}$ and in vitro drug release. Formulation showed slight decrease in entrapment after 30 days of storage. The in vitro drug release from the formulation was also decreased after stability study period. This may be due to decrease in the relative drug content.

\section{Comparative study of multiple emulsion of Atorvastatin with marketed Atorvastatin tablets}

The Multiple emulsions was evaluated for in vitro dissolution study and compared with marketed tablet under same experimental conditions and the data was recorded as a chart in figures.

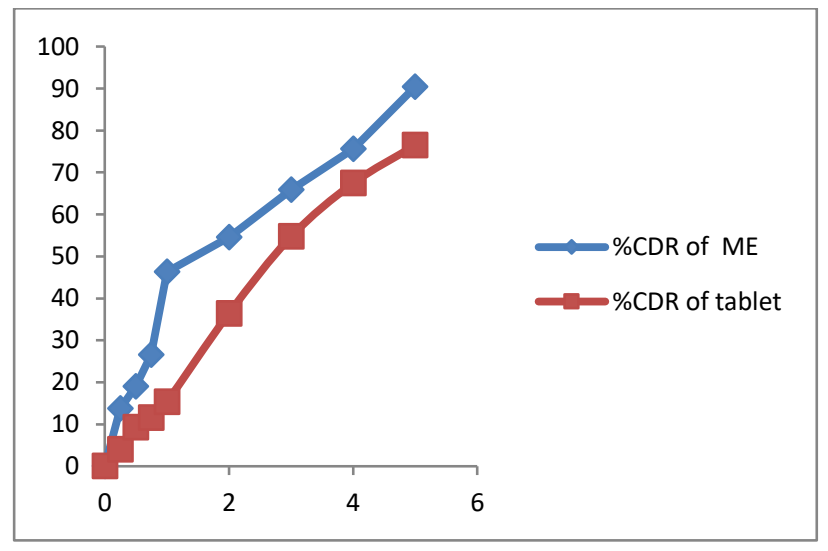

Figure 5: Comparative study of \%CDR of ME \& tablet of Atorvastatin 


\section{CONCLUSION}

The study was aimed at the Formulation, Optimization and evaluation of multiple emulsion of Atorvastatin. Two different non-ionic surfactants were used for the formulation. Atorvastatin, a synthetic HMG Co-A Reductase inhibitor, is widely used in treatment of primary hypercholesterolemia and Dyslipidaemia. ME was prepared by two step emulsification process. The main purpose was to develop stable multiple emulsion with higher solubility \& drug release. The study revealed that multiple emulsions can be optimized for good stability and higher drug release by optimizing different formulation variables like type $\&$ proportion of primary \& secondary emulsifier and phase volume ratio of internal phase: external phase; and process variables like speed $\&$ time of stirring during primary $\&$ secondary emulsification.

This study concludes that Multiple Emulsion formulation can provide consistent and prolonged release of Atorvastatin. It will lead to sustained action of the entrapped drug that reduce the side effects associated with frequent administration of the drug and potentiate the therapeutic effects of the drug.

\section{REFERENCES}

1. Rajeshkumar, Murugesan Senthilkumar, Nanjaian Mahadevan. Multiple emulsion. A Review. International Journal of Recent Advances in Pharmaceutical Research, 2 (1), 2012, 9-19.

2. P.Neeraja, M. Amaleswari and G.Ravali. Formulation and Evaluation of Nifedipine multiple emulsions. International Journal of Pharmaceutical, chemical and Biological sciences, 4(3), 2014, 673-680.

3. Vyas Jiger, Shah Adarsh, Raval Dhaval, Parmar Vijay. Development of stable multiple emulsion of Atorvastatin. International Journal of Applied Biology and Pharmaceutical technology, 2(2), 2014, 19-428.
4. Jyothi Wadhva, Anroop Nair and Rachna kumaria. Emulsion forming drug delivery system for lipophilic drugs. Acta Poloniae Pharmaceutica n Drug Research, 69(2), 2012, 179191.

5. Sumithapaul, Abhineshkumar, Pramod Yadurkar, Kruthikasawant. Design and Development of multiple emulsions for the enhancement of oral bioavailability of Acyclovir. Drug development and Industrial pharmacy, 39(11), 2013, 1808-1817.

6. Vani Madaan, Arsh Chanana, Mahesh kumar kataria, Ajay Bilandi. Emulsion Technology and recent trends in emulsion application. International Research Journal of Pharmacy, 5 (7), 2014, 533-542.

7. Sumana Khosh: Formulation and characterization of multiple emulsions with various additives. International Journal of Research in Pharmaceutical and biomedical sciences, 2 (2), 2011, 751-759.

8. Naveed Akhtar, Muhammad Uzair.Formulation and Characterization of Multiple emulsion containing $1 \%$ Ascorbic acid.Bull. Chem. Soc. Ethiop, 24(1), 2010, 1-10.

9. M Sedef ERDAL, Ahmet ARAMAN. Development and Evaluation of Multiple Emulsion Systems Containing Cholesterol and Squalene. Turkish J. Pharm. Sci, 3(2), 2006; pp.105-121.

10. Dragana D. Vasiljević, Jelena V. Parojčić, Marija M. Primorac AndGordana M. Vuleta. Rheological and droplet size analysis of W/O/W multiple emulsions containing low concentrations of polymeric emulsifiers. Journal of the Serbian Chemical Society, 74 (7), 2009, 801-816.

11. Jisna Sebastian, Noby Thomas, Praveenraj R, boby Johns G, Chacko AJ, Daisy PA. Formulation and evaluation of herbal gel containing the leaf extract of Anacardium occidentale. International journal of pharmaceutical sciences review and research 61(1), march-April 2020, pg 93-97.

Source of Support: None declared.

Conflict of Interest: None declared.

For any question relates to this article, please reach us at: editor@globalresearchonline.net New manuscripts for publication can be submitted at: submit@globalresearchonline.net and submit_ijpsrr@rediffmail.com 